\title{
UN EPISODIO DE LA LUCHA POR EL TEATRO EN EL SIGLO XVIII ESPAÑOL
}

Las historias literarias suelen limitar la controversia teatral de nuestro siglo XVIIr a la lucha entre la escuela tradicional española, inspirada en la libertad del autor y el popularismo de su inspiración, y las tendencias neoclásicas favorecidas por los organismos oficiales; a los historiadores sólo tangencialmente les interesa este aspecto; más de lleno entran en su ámbito otros aspectos desconocidos o mal conocidos: el aspecto sociológico-educativo que instrumentalizaba el teatro convirtiéndolo en recurso educativo para formar buenos ciudadanos y, sobre todo, el conflicto jurisdiccional que enfrentó a los gobernantes ilustrados, en especial Campomanes y el conde de Aranda, con la Iglesia, que pretendía un derecho absoluto de censura previa sobre los espectáculos teatrales e incluso tiraba a su supresión, dentro de un clima de atosigante moralismo en el que tomaron parte muy activa diversos miembros de las órdenes religiosas. Se encontraba bien secundada por las oligarquías municipales, también poco afectas al teatro por motivos a la vez religiosos y sociales; se acusaba a los componentes de la grey farandulesca de zapar los fundamentos de la moralidad de la clase burguesa y apartar del trabajo a la clase obrera.

Estas tensiones alcanzaron su ápice en Andalucía, donde, a excepción de Cádiz, los teatros llegaron a desaparecer casi por completo. "Yo mismo, escribía Blanco White, he visto a un fraile con un crucifijo en la mano pararse a la puerta de un teatro a la cabeza de una procesión nocturna y conjurar al pueblo a que no entrara en aquella mansión de pecado"'. La campaña fue dirigida por el capuchino fray Diego José de Cádiz con éxito casi total en las postrimerías del siglo ilustrado ${ }^{2}$. Fue un gran error de la Iglesia española combatir a muerte el teatro en vez de poner a su servicio este instrumento educativo, como ya lo había hecho la Iglesia medieval y como siguieron haciéndolo los jesuitas en sus cole-

1 Cartas de España, carta IV.

2 No hay un trabajo completo sobre esta faceta de la actuación de fray Diego. Puede consultarse su biografía por fray Sebastián de Ubrique, aunque sus noticias son muy sucintas. 
gios. Los clérigos ilustrados, los que intervendrían en las Cortes de Cádiz, los simpatizantes con las nuevas ideas eran una minoría.

El reinado de Carlos III pudo haber significado una renovación si el monarca hubiera tenido en este punto un criterio personal; pero él, personalmente, a pesar de sus años napolitanos, no sentía ninguna inclinación por la música ni por el arte teatral. Por eso sus ministros actuaron haciendo valer que se trataba de un punto de jurisdicción; así fue como Campomanes consigue la desautorización del vicario eclesiástico de Madrid, que había prohibido la representación de La criada señora, una adaptación de La serva padrona.

La cobertura que en este punto proporcionaban los escritores a los gobernantes era débil. No es una casualidad que la polémica de Juan Pablo Forner contra varios teólogos andaluces en defensa del teatro cayeran en un completo olvido, y que tampoco su más detacado especialista, François Lopez, le haya prestado mucha atención ${ }^{3}$. En los Apuntes sobre el bien y el mal de España del abate Gándara (por citar un ejemplo), que constituye uno de los programas de reforma más completos que se formularon en aquel siglo, sólo encontramos las siguientes líneas referentes al teatro: "Para las representaciones públicas de nuestros teatros se escribirán comedias nuevas arregladas a todos los preceptos del arte y que tengan por argumento las virtudes y acciones más heroicas de nuestros incomparables españoles antiguos" 4 .

Este texto es de 1762. En el mismo año comenzó su carrera como fiscal del Consejo de Castilla D. Pedro Rodríguez de Campomanes, que sería el hombre fuerte del reinado y sólo dejaría la fiscalía para asumir la presidencia del Consejo. A Campomanes, poco interesado en los valores estéticos, le tenía sin cuidado la pugna entre tradicionalistas y neoclásicos; se inclinaba hacia los segundos por su aversión hacia todas las formas de expresión popular, y sin duda esta sequedad de espíritu, disfrazada de celo por la pureza de religión, influyó en su determinación de acabar con las comedias de santos y los autos sacramentales. Le interesaba más el ejemplarismo cívico al que se refería Gándara en las líneas antes transcritas; pero era, sobre todo, su aversión a las prédicas de los misioneros y a la tendencia de los eclesiásticos a invadir áreas que debían estar reservadas a la autoridad civil, lo que le movió a tomar partido con toda la vehemencia de su carácter en aquella polémica, manifestándose no sólo defensor sino apologista del teatro en un momento en que estaba próximo a su total extinción.

Los acontecimientos de 1766 fortificaron en extremo su posición. Explotando el temor que en Carlos III produjeron el motín de Esquilache y los que como secuela surgieron en numerosos puntos de España, le convenció de la existencia de una conspiración contra su persona, ur-

\footnotetext{
3 Su polémica contra varios teólogos andaluces en defensa del teatro está contenida en varios folletos incluidos en el tomo $\mathrm{V}$ de sus obras manuscritas (B.N. de M.).

${ }^{4}$ Almacén de frutos literarios, t. 1, p. 270.
} 
dida por los enemigos de la reforma. Las víctimas de la fortísima reacción acaudillada por Aranda y Campomanes fueron los jesuitas, pero la violencia de la represión atemorizó a todo el estamento eclesiástico, y Campomanes aprovechó esta coyuntura para estimular la apertura o reapertura de los teatros. Por su parte, Aranda introdujo en la Corte y en otras varias ciudades los bailes de máscaras, diversión bien inocente tal como entonces se practicaba, pero que en aquel contexto tomaba el aspecto de una provocación antieclesiástica ${ }^{5}$.

De los avatares de esta política en el área centro-norte de España he proporcionado recientemente algunos datos inéditos, y próximamente espero hacer lo mismo acerca de lo ocurrido en varias ciudades andaluzas ${ }^{6}$. El ámbito correspondiente a los reinos de la antigua Corona de Aragón ha quedado fuera de mi estudio, pero no porque quedara al margen de la "batalla del teatro". Quizás tuvo allí menor intensidad, al menos parece que la actividad de los misioneros populares fue menos intensa; mas si Barcelona fue, juntamente con Madrid y Cádiz, uno de los escasos pilares sólidos de una actividad teatral sostenida durante aquella centuria, en otras ciudades de aquel espacio geográfico se registraron incidentes que demuestran la existencia de un estado de espíritu similar. He aquí algunos botones de muestra:

En Zaragoza se quema el teatro el 11 de noviembre de 1778 , en plena función, causando gran cantidad de víctimas, y el capuchino fray Bruno de Zaragoza tuvo la osadía de celebrar el aniversario de este luctuoso suceso con un sermón en el que atribuía la tragedia a castigo celestial por haber profanado la ciudad de la Virgen del Pilar con tan abominable espectáculo ${ }^{7}$.

En Orihuela el obispo D. José Tormo consigue orden de suspensión y posterior derribo del teatro de esta ciudad. La misma campaña condujo en el resto de su arzobispado, que comprendía otras ciudades importantes, como Elche y Alicante. En Elche obtuvo en 1777 la revalidación de un acuerdo hecho por el ayuntamiento en 1735 prohibiendo las comedias ${ }^{8}$.

En Valencia el arzobispo D. Andrés Mayoral aprovechó el espanto que causó a los habitantes el furioso temporal de 1746 para que la ciudad hiciera promesa de suspender las comedias, "mas dicho Sr. Arzobispo no se contentó con que esto fuera por tiempo sino que negoció

${ }^{5}$ Hubo bailes de máscaras en Madrid, Barcelona, Sevilla, Cádiz, Alicante, Cartagena, Orihuela, Valencia, Murcia y La Coruña. Se suprimieron en octubre de 1773 a petición del ayuntamiento de Madrid, que dijo habían degenerado por la intrusión de gentes de baja esfera, lo que causó el retraimiento de las de mayor lustre, "que era para quienes se habían establecido" (A.G.S. Gracia y Justicia, legajo 993).

6 A. Domínguez Ortiz, "La batalla del teatro en el reinado de Carlos III", ALE, 2 (1983), 177-196.

7 "Representación del juicio a ocasión de haberse incendiado el teatro de las comedias en la ciudad de Zaragoza. Sermón predicado el primer lunes de Quaresma inmediata a este suceso en la Santa Iglesia de la Seo". Año 1780, 55 pp.

8 G. Vidal Tur: Un obispado español: el de Orihuela-Alicante, Alicante, 1961, t. 1. 
en Madrid que se prohibieran, y para quitar la ocasión de que por adelante las intentaran derribó la hermosa casa y corral que havía para ellas en la que aún se llama plaza de las Comedias, que havía sido regalada por el célebre padre Tosca, y en su lugar fabricó las casas que se ven en dicha plaza"'.

En Lérida el obispo, en 1766, prohibió bajo excomunión las representaciones teatrales. Y llegamos así a tomar contacto con el documento que motiva las presentes líneas. Los archivos deparan muchas sorpresas; con demasiada frecuencia se echa en falta el documento que se busca, y a veces sucede lo contrario; se encuentra lo que menos se espera. ¿Por qué extraños caminos llegó a un legajo del Archivo de Indias de Sevilla ${ }^{10}$ una carta del Capitán General de Cataluña al obispo de Lérida con motivo del incidente que acabamos de mencionar? No me es posible averiguarlo ni tampoco tendría mucho interés para nuestro objeto, limitado a un sucinto análisis de dicha carta, en la que se transparenta la actitud de los gobernantes ilustrados ante una cuestión que los estaba enfrentando con una fracción quizás mayoritaria del clero. Digamos primero que el Capitán General de Cataluña no era sólo la autoridad militar más elevada; como sucesor de los antiguos virreyes, abolidos por la ley de la Nueva Planta que acabó con los fueros catalanes, presidía la Audiencia, supremo órgano gubernativo y judicial. Era, por consiguiente, el máximo representante de la autoridad real. Lo era entonces el marqués de la Mina, cuyo mando dejó honda huella en el Principado ${ }^{11}$. La carta revela su carácter a la vez firme y conciliador; está fechada en Barcelona, 11 de noviembre de 1766, es decir, cuando la ofensiva de Campomanes en favor del teatro era más fuerte, pero su estilo no tiene la dureza del asturiano; comienza su carta recordando al prelado que es temerario fulminar censuras sin discriminación contra la representación de comedias; el mismo rey las autoriza con su presencia; se representan en su palacio. En todo el orbe cristiano los príncipes, incluso los prelados, las fomentan "para embeleso del público y para desterrar el ocio". En Barcelona siempre se han representado sin que el prelado haya excomulgado a los cómicos. "Las hay también en el país donde V.S.I. nació (Aragón) y siendo auxiliar del llmo. Agüero se representaron en Zaragoza'.

Pasa luego a las circunstancias particulares del país catalán: “Cataluña es una de las provincias más pobladas y de las que más producto rinde a S.M. Sus naturales son laboriosos, pero aman en su tiempo la diversión, y así como en el Carnaval son festivos, son devotos en la Quaresma, y no se pueblan menos que los paseos, los bayles y los teatros, las iglesias y las procesiones. Sus genios son adustos y férreos, se obstinan en lo que aprehenden, y son tan llanos al buen trato como duros

\footnotetext{
9 Vicente de Orellana, Noticias curiosas, ms. Almarche, núm. 113.

10 Indiferente General, legajo 3.164, tercera parte.

11 J. Mercader, Els Capitans Generals, Teide, Barcelona Biografies catalanes, 10).
} 
a la violencia". Basándose en estos principios le insinúa las bases de un posible arreglo que no signifique para nadie una humillación. Le ruega que deje en suspenso la excomunión, y en cambio le promete que se quitará de las comedias, bailes y entremeses lo que le parezca moralmente reprobable. "Insinúelo V.S.I. al gobernador de esa plaza, que al instante lo conseguirá, y así se lo prevengo, y al ayuntamiento". Y termina con esta máxima, muy propia de un gobernante ilustrado: " $\mathrm{La}$ multitud no se gobierna siempre por lo mejor. Contentémonos si se consigue lo bueno".

Ignoro el desenlace de este episodio, que será fácil hallar en fuentes leridanas. Por lo demás, en esta materia tienen más valor las actitudes que los hechos.

Antonio Domínguez Ortiz 